\title{
ТРУД В СОВРЕМЕННОМ ГЛОБАЛЬНОМ МИРЕ
}

\section{WORK IN A MODERN GLOBAL WORLD \\ O. Karpova}

Summary: Work exists in all societies and, despite the development of technological progress, which facilitates work any state can't completely get rid of the need to work. The problem of modern attitude toward work in culture is not widely studied in the Russian research literature. At the same time, it is very important to systematize and analyze the main concepts affecting the current situation of labor in the global world in order to form a new cultural policy that must change and adapt to global changes. The article pays special attention to the concepts of $Z$. Bauman and U. Beck. For the analysis of the place of work, five main aspects are identified: sociological aspect, territorial fixity, unemployment, the ratio of productive and unproductive labor, as well as satisfaction from labor activity.

Keywords: work, labor, globalization, attitude to work, post-industrial society, unemployment.

\author{
Карпова Ольга Евгеньевна \\ Аспирант, Санкт-Петербургский \\ государственный университет \\ oevkarpova@gmail.com
}

Аннотация: Труд существует во всех обществах и, несмотря на развитие технического прогресса, который облегчает работу, полностью избавиться от необходимости трудиться, не может ни одно государство. Проблема современного отношения к труду в культуре недостаточно широко исследована в отечественной научной литературе. При этом систематизировать и проанализировать основные концепты, затрагивающие текущее положение труда в глобальном мире, очень важно для формирования новой культурной политики, которая должна меняться и адаптироваться к глобальным изменениям. В статье уделено особое внимание идеям 3. Баумана и У. Бека. Для анализа места труда выделено пять основных аспектов: социологический аспект, территориальная фиксированность, безработица, соотношение производительного и непроизводительного труда, а также удовлетворение от трудовой деятельности.

Ключевые слова: труд, глобализация, отношение к труду, постиндустриальное общество, безработица.

дустриальная культура имеет ряд новых характеристик, к которым относится инновационность производства, глобализация экономики, рост сектора услуг, роботизация и вытеснение человека из рутинной деятельности, а в связи с этим сокращение рабочих мест и увеличение количества людей занятых прекарной [2, р. 1] (незащищенной никакими социальными гарантиями) работой, и в то же время появление новых специальностей и профессий.

Чтобы определить место труда в современной культуре глобального мира, мы будем рассматривать его по следующим аспектам: социологическое осмысление труда, территориальная фиксированность работы, проблема отсутствия труда или безработица, соотношение производительного и непроизводительного труда и примыкающая к этой проблеме иерархия профессий, а также удовлетворение от трудовой деятельности. Методологической основой является анализ концептов исследователей вопроса труда в глобальном мире.

\section{Сочиологическое осмысление труда}

Если обратить внимание на социологические концепции труда, то выделяются работы 3. Баумана и У. Бека как одни из наиболее оригинальных. Бауман предложил взять за основу две новые характеристики глобального мира текучесть и индивидуализацию. В своих работах «Текучая современность» и «Индивидуализированное общество» Бауман подробно исследует, какие измене- 
ния произошли в индивидуальности и труде. С точки зрения Баумана, время тяжелой современности с неповоротливым индустриальным производством, ясностью карьерных перспектив уходит в прошлое, и на его место приходит текучая современность или текучая модернити. Выстраивается новое самовосприятие человека: в США и странах Западной Европы человек растет и развивается, уверенный в собственной ответственности за свою судьбу. Теперь благодаря глобализационным процессам такая точка зрения становится популярна и в России.

Еще одна оригинальная концепция, характеризующая глобальный мир, представлена У. Беком. Будучи одним из авторов концепта «общества риска», Бек говорит, что современный капитализм неотделим от производства рисков.

Индустриальный способ производства не учитывал возникающие риски, однако в современном мире благодаря техногенным катастрофам стало понятно, что погоня за выгодой является лишь сиюминутной, а экономический рост любой ценой угрожает существованию всей человеческой цивилизации. Именно в XX веке стало ясно, что человечество может уничтожить само себя не только по причине техногенных катастроф, какой, например, стала Чернобыльская авария, но и путем методичного, ничем не сдерживаемого и неконтролируемого производства. Рост богатства идет рука об руку с производством рисков.

Бек выделяет тенденции, которые привели к современному отношению к труду: динамика в сторону индивидуализации после Второй Мировой Войны, малая значимость классового деления общества, изменение положения мужчины и женщины. Массовая безработица больше не связана с классовым характером. Эмансипация женщин открывает гораздо больше возможностей перед ними, однако ведет к скрытому неравенству (так как за женщиной закрепляется приоритетная обязанность заботиться о детях и пожилых родственниках, что ставит женщин в тяжелое положение при разводе).

Другой взгляд на новое положение труда представляет современный экономист Р. Флорида - автора теории креативного класса. Флорида выделяет новые черты экономической организации современного глобального мира, переживающего последствия кризиса или Великой рецессии 2008 года. С точки зрения исследователя, кризисы открывают периоды технологических инноваций, а развивающийся инновационный потенциал, в свою очередь, улучшает экономическую эффективность. Однако экономическая эффективность не гарантирует облегчения труда или снижение его энергозатратности и интенсивности. «Многие из замечательных изобретений того периода были призваны облегчить труд, но, по иронии, увеличивали его объем» [3, с. 34] - подмечает Флорида.

\section{Территориальная фиксированность работы}

Текучая модернити характеризуется изменением территориальной фиксированности человека. Бауман называет это «... реванш[ем] кочевого образа жизни над принципом территориальности и оседлости». [4, с. 20] C точки зрения исследователя отныне выгоднее не иметь собственности, быть мобильным, в любой момент уехать в другой город или даже страну, если перспективы получить желаемое выше.

Намечается тенденция по отказу от владения движимым и недвижимым имуществом. Вслед за 3. Бауманом P. Флорида доказывает, что собственность только замедляет экономического агента, делает последнего менее гибким. Появляются новые формы инфраструктур (территория от Шанхая до Пекина, от Бостона да Нью-Йорка), которые привлекают большое количество работающих людей и становятся новой формой пространственной фиксации, в основном в непроизводственном секторе.

Другой важной особенностью индивидуализированного общества становится дематериализация труда, создающего капитал. Отныне капитал не привязан к месту, а значит и к людям, населяющим это место. И если человек не может или не хочет последовать вслед за капиталом, работодатель будет использовать работников другого города или другой страны. Этот процесс имеет обратную сторону и для капитала: современный индивидуализированный человек так же не испытывает ни привязанности, ни чувства долга к работодателю. Более того, теперь он не относится к профессии как к «делу жизни», «призванию», о котором говорил М. Вебер [5, с. 82], и вполне допускает, что сменит несколько профессий в течение своей жизни. Поэтому работодатель создает корпоративную культуру, чтобы внушить работнику привязанность и чувство долга перед компанией.

Другой важной особенностью территориальной фиксированности труда становится развитие удаленной работы. Все больше людей непроизводительного интеллектуального труда могут работать, где угодно.

\section{Проблема отсутствия труда}

В государствах всеобщего благосостояния (Welfare State) безработных поддерживали, потому что считали их «резервной армией». Однако сейчас, благодаря развитию технического прогресса, необходимость в этой «резервной армии» свободной рабочей силы отпала, и это повлияло на кризис государств с подобной политикой $[6$, с. 166]. Формируется пассивное и иждивенческое общество [6, с. 123]. 
Благодаря мощно развивающемуся техническому прогрессу и выводу производства в развивающиеся страны большая часть людей, составляющих кадровый резерв, не смогут снова найти себе работу по специальности, а осваивать новую профессию не всегда возможно в рамках возраста и способностей [7, с. 93]. Бауман так же неутешительно продолжает, что потребители диктуют векторы развития экономики, а «бедняки не представляют ценности и в качестве потребителей» [4, с. 94]. Таким образом «новыми бедными», с точки зрения Баумана, являются люди лишенные власти, по причине отсутствия оплачиваемой работы, а значит и дополнительного дохода. Бек вторит Бауману, замечая, что безработица настигает человека, как «личная судьба» $[8$, с. 132].

С точки зрения Баумана, низкоквалифицированные работники безоружны перед текучим капиталом, но и вряд ли объединятся в серьезную политическую силу по причине расслабляющего воздействия СМИ, привлекательности общества потребления, а также отвлекающего эффекта общества зрелищ и развлечений.

К проблеме безработицы примыкает проблема прекаризации (рост незащищенного социальными гарантиями труда с неясными перспективами). Несмотря на то, что Г. Стэндинг называет прекариат «новым опасным классом» в одноименной работе, прекаризация не является новым явлением, присущим лишь постиндустриальному обществу, тем не менее, сейчас она приобретает новые особенности не похожие на те, что были ранее. В первую очередь главная причина роста прекарной занятости - это избыток предложения трудовых услуг и ежегодное сокращение спроса на них на рынке труда. Рабочих мест будет не хватать на всех и за возможность заниматься хоть какой-то трудовой деятельностью придется конкурировать.

Количество вакансий можно увеличить, создав дополнительные вакансии в области полезной гражданской деятельности (уход за больными, престарелыми, инвалидами и т.д.), однако кто-то должен оплачивать этот труд (кто должен оплачивать государство или независимые фонды - вопрос дискуссионный).

\section{Производительный и непроизводительный трум и иерархия профессий}

Почти во всех странах отношение к физическому труду колеблется от презрительного до почетного, но все же весьма тяжелого и непредпочтительного при свободном выборе. Г. Браверман, последователь марксистского отношения к труду, говорит о «деградации труда» [9, с. 307], то есть утрате специальных навыков рабочих, упрощении их работы, в связи с введением все новых технических средств, выхолащивание смысла работы, низве- дение работника до уровня машины. В станах Америки и Западной Европы престижность непроизводительного труда становится значительно выше, чем стандартного труда рабочего, а в связи с глобализацией и во всем мире. Но для того, чтобы получить возможность зарабатывать умственным трудом, часто необходимо получить специальное образование. Тем не менее, образование не гарантирует работу по специальности.

Бек говорит о проблеме «призрачного вокзала» - невозможности найти работу по специальности, приложив к ней много сил, например, получив специальное образование и пройдя неоплачиваемую стажировку.

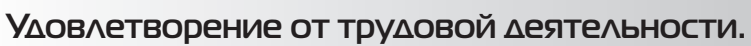

Работник, как и прежде, ждет от труда удовлетворения своих материальных нужд. Однако теперь работа, с точки зрения Баумана, «...измеряется и оценивается по способности быть интересной и занимательной, удовлетворяющей не столько этическое, прометеево призвание производителя и создателя, сколько эстетические потребности и желания потребителя, искателя острых ощущений и коллекционера переживаний» [4, с. 151]. Трудоцентризм постепенно уходит в прошлое не только потому, что существовать на нетрудовые доходы могут позволить себе уже большее количество людей, чем в индустриальном и, тем более, традиционном обществе, но из-за смены приоритета индивида в сторону поиска себя и творческой самореализации в различных сферах. Г. Могилевская и вовсе считает, что «право на существование обретает только тот труд, который приносит удовольствие, труд как игра, в то время как труд-напряжение вытесняется из сознания, превращается в скучный, необязательный придаток человеческой жизни» [10, с. 127]. Несмотря на спорность подобного утверждения, такая тенденция существует, особенно среди молодежи, однако говорить о том, что она является определяющей в выборе работы, пока невозможно.

Работа - это то, чем «человечество при создании своей истории занималось согласно своей судьбе, а не свободному выбору» [4, с.148]. И несмотря на то, что сейчас появляется больше возможностей для самореализации в выборе профессии, и работы, для большей части людей определение Баумана, по-прежнему, остается справедливым.

\section{Основные особенности труда в глобальном мире}

Суммируем основные выводы, что изменилось в постиндустриальном обществе на основе концептов, приведенных выше. Несмотря на ярко выраженный трудоцентризм современного общества, его целесообразность все больше вызывает сомнения. 
Рост прекарной занятости и связанные с этим серьезные проблемы становится постоянным спутником глобального мира. Как реакция на это в культуре начинает с новой силой преобладать культ успеха и как противоположность - настроения, связанные с получением пассивного дохода без применения труда, а также дауншифтинг. Глобализация диктует свои правила труду, обрекая на низкооплачиваемый и незащищенный труд целые страны: неизбежно происходит сокращение рабочих мест, связанных с рутинной деятельностью - ее уже выполняют программы. Отсюда количество людей, незащищенного социальными гарантиями труда будет расти, труд с социальными гарантиями станет наградой и привилегией. Творческий труд (разработка идей) - пока единственная область, в которой человека невозможно заменить машиной - машина работает только в рамках заданной программы.

Уже давно ведутся разговоры о безусловном базовом доходе, который позволил бы людям существовать, не борясь за трудовое место. Уровень жизни жителей стран с развитой экономикой уже позволяет им частично заниматься работой ради удовольствия. Однако внедрение в культуру мысли о необходимости общественно полезного труда для собственного блага человека остается, по-прежнему, открытым и требует решения.

Труд, по-прежнему, занимает много времени в жизни человека и от того, как человек сможет организовать свою деятельность, зависит его счастье и благополучие.

Труд остается культурной универсалией и формирует идентичность большинства людей. Особенностью современного трудоцентризма в России является советское индустриальное наследие. В Советском Союзе появляется доктрина всеобщности труда. Человек становится привязанным к заводу или другому месту работы. Люди, жившие в эпоху героизации труда, воспитывали так же своих детей. Многие современники помнят статью 209 УК РСФСР, за которую грозили исправительные работы. В современной России ответственность за сознательный отказ от трудоустройства не наступает, но при этом работа, а точнее, получаемая за нее заработная плата, является основным источником средств к существованию большинства россиян, а также один из важнейших способов конструирования своей идентичности и смысла жизни.
В современном обществе все сложнее выбрать выигрышную стратегию построения карьеры, так же о преданности делу, а тем более компании можно говорить лишь в очень малом количестве профессиональных областей. Тем не менее, человек по-прежнему идентифицирует себя чаще всего именно по профессии, которой он занимается.

Труд все меньше привязан к какому-то определенному месту. Временная занятость, фриланс, работа над проектами становятся все более распространенными. Люди все чаще начинают снова трудиться дома: однако если в традиционном обществе «дома» трудились работники физического труда (крестьяне, ремесленники), то теперь дома трудятся в основном работники непроизводительного труда.

Сфера услуг и непроизводственный труд становится все более распространенным, для производства и сельского хозяйства больше нет необходимости в большом количестве работников.

Свойством отношения к труду в постиндустриальном обществе становится поиск не только работы, обеспечивающей определенный уровень дохода, но и поиск максимально интересного и перспективного занятия.

Рост безработицы в развитых странах ведет к пересмотру отношения политики социального государства.

Профессии, связанные с физическим трудом и заменяемые машинами, становятся непрестижными и ненадежными.

В заключение можно сослаться на слова философаперсоналиста Мунье о деятельности: «что мы требуем от деятельности? Изменить внешнюю реальность, сформировать нас самих, сблизить нас друг с другом и обогатить мир наших ценностей» $[11$, с. 106]. Именно на это направляется декларируемый вектор развития отношения к труду в обществе: к преодолению отчуждения, к творческому подходу, к саморазвитию. Однако невозможность повлиять на ход событий из-за сосредоточения большого капитала в руках небольшой группы людей, не позволяет надеяться на благополучный исход в ближайшее время.

\section{ЛИТЕРАТУРА}

1. Белл Д. Грядущее постиндустриальное общество. Опыт социального прогнозирования. Moсква: Academia, 2004. С. 63.

2. Kalleberg, A., Vallas, S. Probing Precarious Work: Theory, Research, and Politics //Research in the Sociology of Work. 2017. 2017. Vol. 31 . p. 1.

3. Флорида Р. Большая перезагрузка. Как кризис изменит наш образ жизни и рынок труда. Москва: Классика-XXI, 2012. С.34.

4. Бауман 3. Текучая современность. Санкт-Петербург: Питер, 2008. С. 20. 
5. Вебер М. Избранные произведения. Москва: Прогресс, 1990. С. 82.

6. Сидорина Т.Ю. Государство всеобщего благосостояния: от утопии к кризису. Москва: РГГУ, 2013. С. 166.

7. Бауман 3. Индивидуализированное общество. Москва: Логос, 2002. С.93.

8. Бек У. Общество риска. На пути к другому модерну. Москва: Прогресс-Традиция, 2000. С. 132.

9. Braverman H. Labor and Monopoly Capital: The Degradation of Work in the Twentieth Century. New York: Monthly Review Press. 1974. P. 307.

10. Могилевская Г.И. «Смерть труда»: постмодернистская рефлексия и реалии. // Исторические, философские, политические и юридические науки, культурология и искусствоведение. Вопросы теории и практики в 2-х ч. Ч. I № 3 (17): 2012. С. 127.

11. Мунье Э. Персонализм. Москва: Искусство, 1992. С. 106.

() Карпова Ольга Евгеньевна (oevkarpova@gmail.com).

журнал «Современная наука: актуальные проблемы теории и практики»

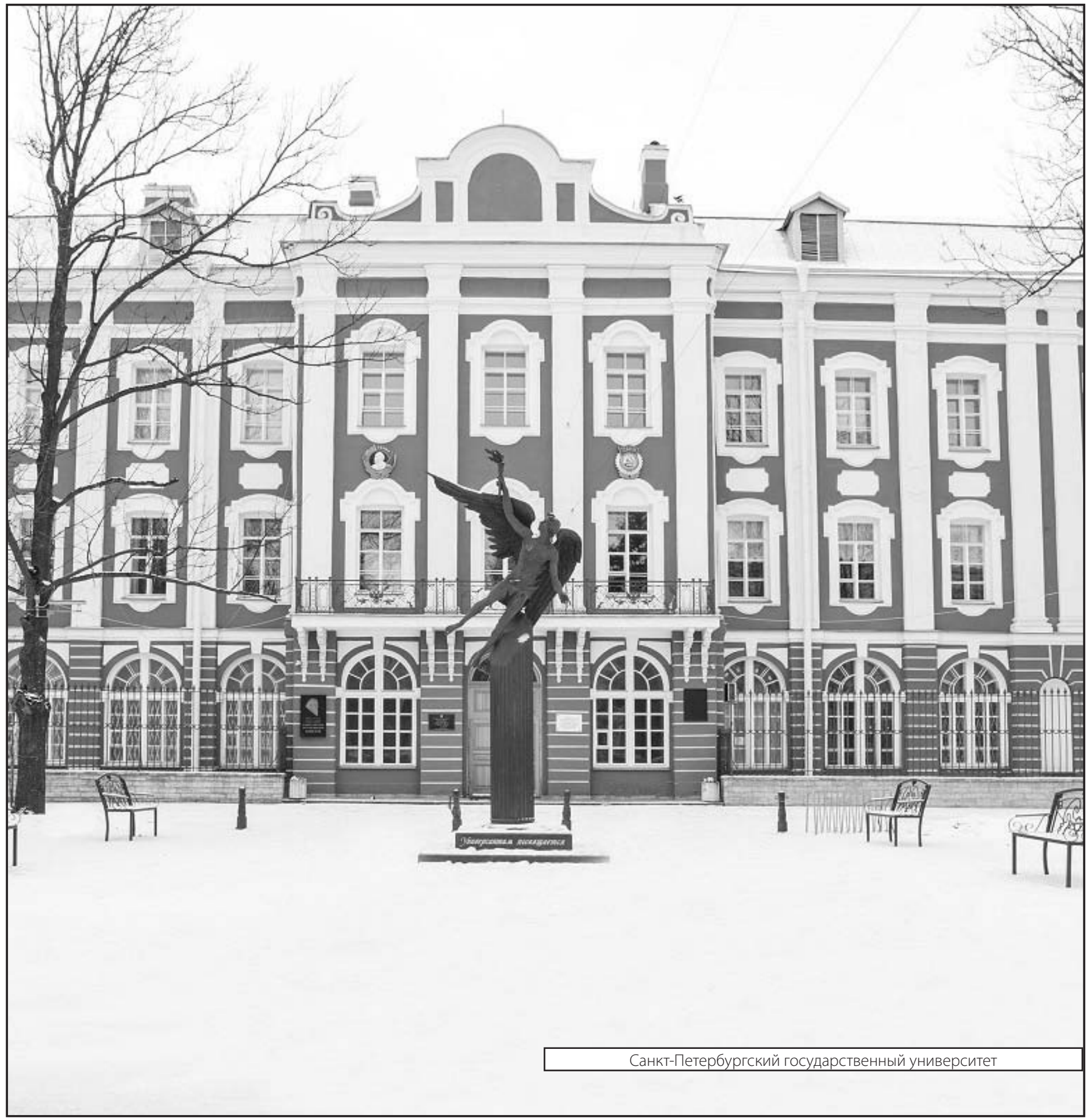

